\title{
The Color Origin of Gem Diaspore: Correlation to Corundum
}

Che Shen and Ren Lu

Color-change diaspore, known commercially as Zultanite, is sought by designers and consumers for its special optical characteristics, namely its color and color change. Understanding the color origin of gem-grade diaspore could provide a scientific basis to guide its gemological testing, cutting, and valuation. This study uses ultraviolet-visible (UV-Vis) spectra and laser ablation-inductively coupled plasma-mass spectrometry (LA-ICP-MS) to examine the color origin of color-change diaspore and to compare it with corundum. As Raman spectra vibration intensities are closely related to crystal direction for diaspore, crystal orientation was determined through Raman spectroscopy. The color correlation between color-change diaspore and corundum confirmed the identity of each chromophore. In addition, the effectiveness of different chromophores such as $\mathrm{Cr}^{3+}, \mathrm{Fe}^{3+}, \mathrm{Fe}^{2+}-\mathrm{Ti}^{4+}$ pairs, and $\mathrm{V}^{3+}$ between gem-quality diaspore and corundum is compared quantitatively.

$\longrightarrow$ em-quality diaspore occupies an important position in the gem market due to its rarity, striking pleochroism, and color-change phenomenon (figure 1). The material's value depends on these factors. A clear understanding of color origin offers considerable benefits for gemological testing, cutting, and even valuation of gem diaspore.

By replacing the major elements in definite structural units through isomorphous substitution, trace elements play an important role in the color of gemstones. The $\mathrm{AlO}_{6}$ octahedra is a significant structural unit that produces color when different trace elements substitute for Al. For example, $\mathrm{Cr}^{3+}$ substitutes for $\mathrm{Al}^{3+}$ in the $\mathrm{AlO}_{6}$ octahedra in jadeite and spinel, causing green and red color (Lu, 2012; Malsy, 2012), while the substitution of $\mathrm{Fe}^{3+}$ for $\mathrm{Al}^{3+}$ in sapphire produces yellow color (Emmett et al., 2003).

Diaspore and corundum have a similar chemical composition and crystal structure (see figure 2). Diaspore, with the chemical formula $\mathrm{AlO}(\mathrm{OH})$, belongs to the orthorhombic space group 2/m 2/m 2/m (Hill, 1979); corundum, with the chemical formula $\mathrm{Al}_{2} \mathrm{O}_{3}$, belongs to the trigonal space group $\overline{3} 2 / \mathrm{m}$ (Lewis et al., 1982). The crystal structure of diaspore consists of $\mathrm{AlO}_{4}(\mathrm{OH})_{2}$ octahedra, whereas the corundum crystal

See end of article for About the Authors and Acknowledgments.

Gems \& GemOlogr, Vol. 54, No. 4, pp. 394-403,

http://dx.doi.org/10.5741/GEMS.54.2.394

(C) 2018 Gemological Institute of America structure consists of $\mathrm{AlO}_{6}$ octahedra (Hill, 1979; Lewis et al., 1982). Both types of crystals are composed solely of octahedral units. In addition, the diaspore structure is able to convert to corundum structure through dehydration (Iwai et al., 1973). Due to their closely related crystallographic structure and chemical composition,

\section{In Brief}

- Gem-quality diaspore with an attractive color and remarkable color-change phenomenon is rare and often highly valued.

- The $\mathrm{AlO}_{6}$ octahedral structural unit, a very important structural unit related to gemstone color, is very similar between diaspore and corundum.

- The structural similarity between diaspore and corundum helps us confirm the color origin of diaspore quantitatively.

we may speculate that there is also a close color correlation. There are two other reasons for this hypothesis:

1. Compared to other gemstones containing the $\mathrm{AlO}_{6}$ octahedral structural unit, diaspore and corundum share the closest similarity in average Al-O bond length, octahedral volume, and degree of distortion of octahedral sites (quantified by determining the octahedral quadratic elongation). For specific data, refer to table 1. 

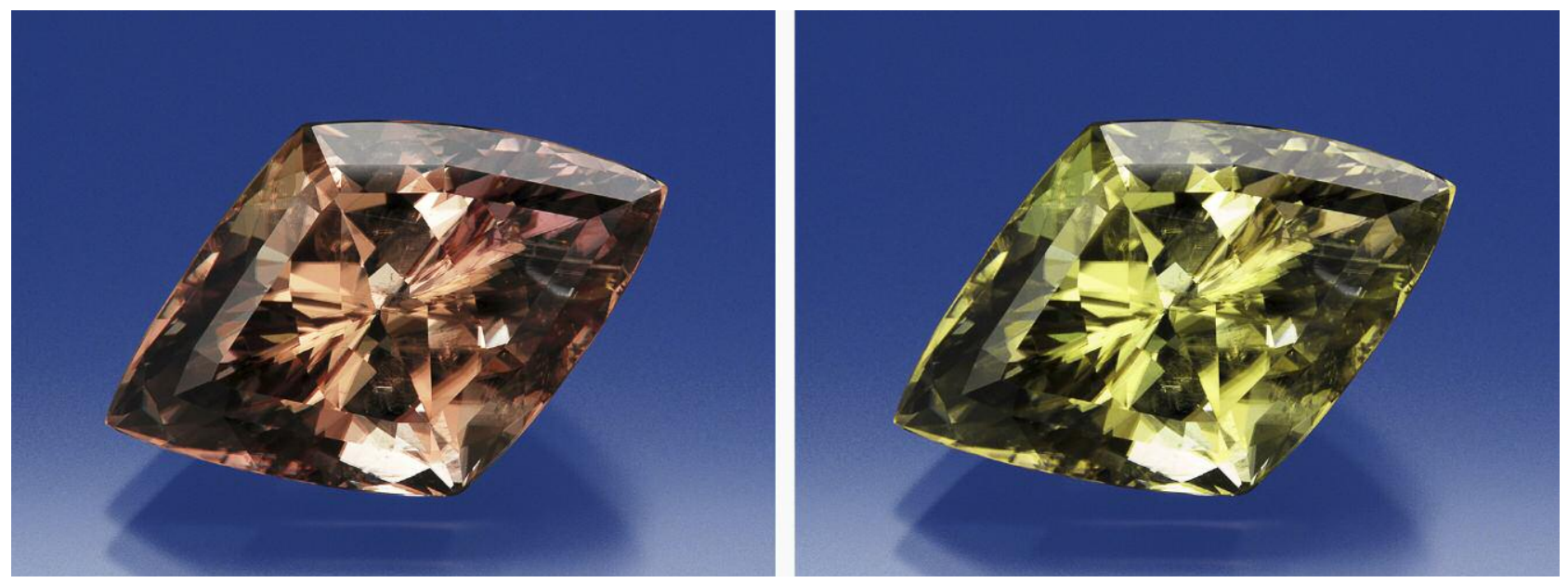

Figure 1. This $24.60 \mathrm{ct}$ color-change diaspore is shown under D65 illumination (left) and A illumination (right). Photos by Robert Weldon, courtesy of Zultanite Gems LLC.

2. The structural similarity between corundum and diaspore was first referred to by Deflandre (1932). Both diaspore and corundum are connected by octahedral units, and both contain edge-shared octahedra. However, there are faceshared octahedra along the c-axis that only exist in corundum, and this is the main difference between the two. Other related studies involving $\mathrm{X}$-ray powder photography (Francombe and Rooksby, 1959|, single-crystal X-ray techniques, scanning electron microscopy (SEM), and hightemperature optical microscopy (Iwai et al., 1973) have confirmed a structural similarity between the two gem materials.

This intensely close relationship between corundum and diaspore with respect to the octahedral $\mathrm{Al}$ site and their overall structural similarity indicates that chromophores substituted into the $\mathrm{Al}$ site of both materials are expected to present similar UV-visible absorption features. Consequently, this study adopts an analogy to address the color origin of diaspore by quantitatively analyzing the trace-element chemistry in diaspore from two geographic origins-Myanmar (formerly Burma) and Turkey-and comparing them with high-quality natural and synthetic corundum. The research aims to use the color correlation between diaspore and corundum to confirm the color origin of gem diaspore.

\section{MATERIALS AND METHODS}

Samples. Nine diaspore samples from Turkey were purchased from a gem dealer at the Beijing International Jewelry Show in November 2016. Forty slices of diaspore were collected in the field from Mogok, Myanmar, by author RL. All samples were prepared as wafers. These wafers are perpendicular to the aaxis, b-axis, and c-axis, respectively. Photos of samples are shown in table 2 .

Raman and Photoluminescence (PL) Spectroscopy. Raman and PL spectra were collected from the samples with a Renishaw inVia Raman microscope system at the Gemstone Center of Hebei GEO University in China. Raman spectra were collected from 100 to $1400 \mathrm{~cm}^{-1}$ using Nd-YAG laser excitation, producing highly polarized light at $532 \mathrm{~nm}$

TABLE 1. Crystallographic parameters of corundum, diaspore, and spinel.

\begin{tabular}{lcccccc}
\hline Gemstone & $\begin{array}{c}\text { Average } \\
\text { distance of } \\
\text { Al-O }(\AA)\end{array}$ & $\begin{array}{c}\text { Octahedral } \\
\text { volume }\left(\AA^{3}\right)\end{array}$ & $\begin{array}{c}\text { Octahedral } \\
\text { quadratic } \\
\text { elongation }\end{array}$ & $\begin{array}{c}\text { Deviation of average Al- } \\
\text { O distance }(\% \text { difference } \\
\text { from corundum) }\end{array}$ & $\begin{array}{c}\text { Deviation of octahedral } \\
\text { volume }(\% \text { difference } \\
\text { from corundum) }\end{array}$ & $\begin{array}{c}\text { Deviation of quadratic } \\
\text { elongation (\% difference } \\
\text { from corundum) }\end{array}$ \\
\hline Corundum & 1.9133 & 9.0754 & 1.0202 & 0 & 0 & 0 \\
Diaspore & 1.9154 & 9.1042 & 1.0203 & 0.10976 & 0.31734 & $9.8020 \times 10^{-3}$ \\
Spinel & 1.9327 & 9.4955 & 1.0092 & 1.0140 & 4.6290 & 1.0782 \\
\hline
\end{tabular}

Note: The crystallographic parameters are from Lewis et al. (1982), Hill (1979), and Peterson et al. (1991). 

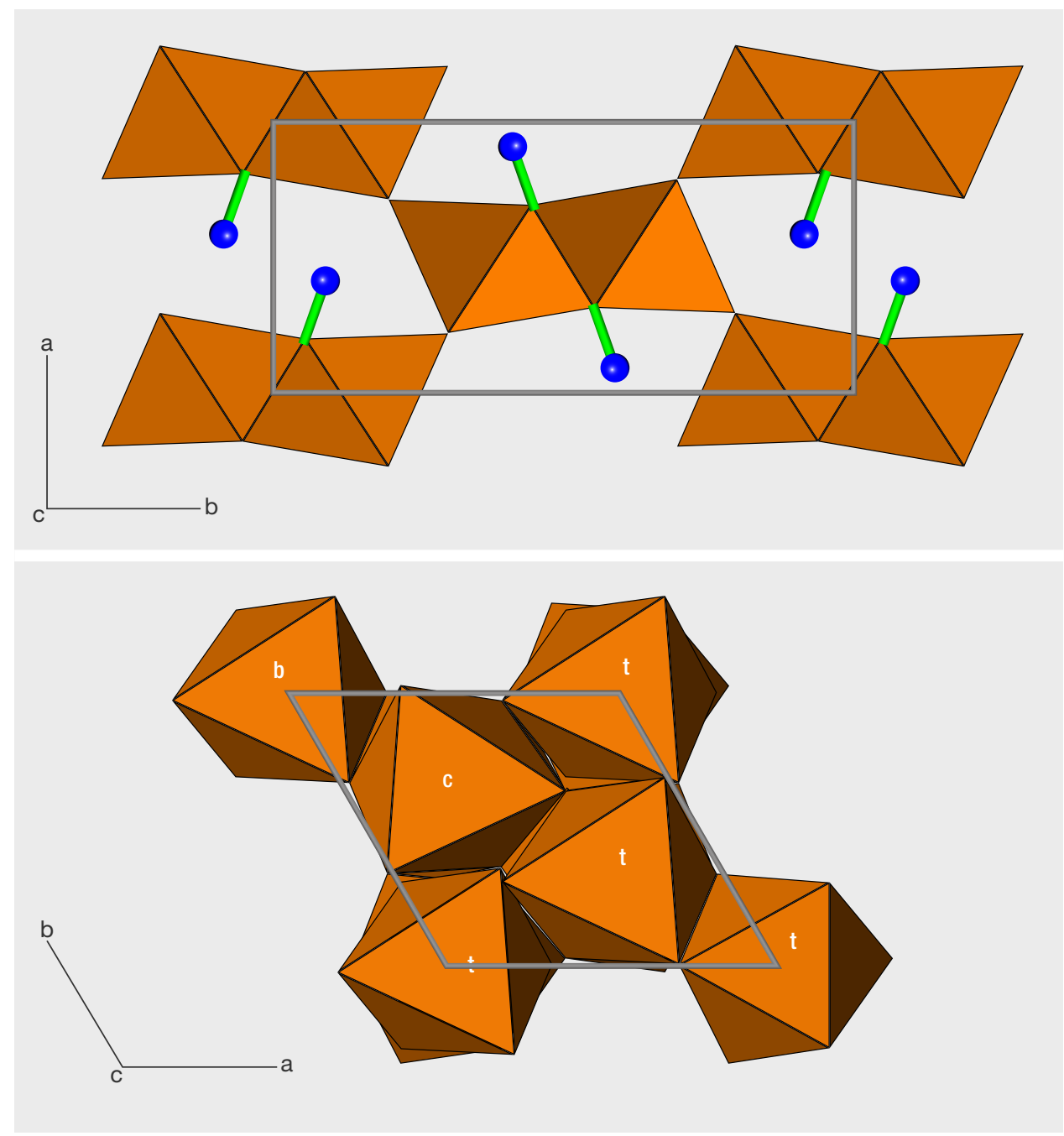

Figure 2. These views of the crystal structure of diaspore (top) and corundum (bottom) illustrate the basic building blocks, $\mathrm{AlO}_{4}(\mathrm{OH})_{2}$ and $\mathrm{AlO}_{6}$ octahedra, and their geometric relationships. The crystallographic orientation is shown in the upper left corner projected down the c-axis. The blue spheres in the diaspore's crystal structure represent the hydrogen atoms. The structure is characterized by edge-shared octahedral double-chains, which are extended along the a-axis. The corner-linked octahedral layers are connected along the aaxis. In addition, the $\mathrm{OH}$-vector is approximately parallel to the a-axis. In the crystal structure of corundum, each octahedron is edge-shared, with three octahedra in the $a-b$ plane. All octahedra are face-shared, with one octahedron along the $c$ axis. The letters b, c, and $\mathrm{t}$ represent the different layers in corundum (bottom, center, and top). Based on Hill (1979) for diaspore and Lewis et al. (1982) for corundum.
(1800 lines/mm grating, $10 \mathrm{~s}$ ). The orientation of all samples was carefully controlled. The polarization direction of the injected laser was parallel to the aaxis, b-axis, and c-axis. The $600-800 \mathrm{~nm}$ spectral ranges for Raman photoluminescence analysis (under liquid nitrogen conditions) were excited by an $\mathrm{Nd}$ YAG laser at $532 \mathrm{~nm}$ (1800 lines/mm grating, $10 \mathrm{~s})$.

LA-ICP-MS Analysis. For trace-element analysis, we used an Agilent 7900a ICP-MS coupled with a deepUV laser at $193 \mathrm{~nm}$ excitation at the State Key Laboratory of Geological Processes and Mineral Resources, China University of Geosciences in Wuhan. NIST glass standard SRM 610 and USGS glass standards BHVO-2G, BIR-1G, and BCR-2G were used for external calibration. Ablation was achieved using a $44 \mu \mathrm{m}$ diameter laser spot size, a fluence of around $5 \mathrm{~J} / \mathrm{cm}^{2}$, and a $6 \mathrm{~Hz}$ repetition rate. The diaspore was initially standardized internally with ${ }^{27} \mathrm{Al}$ using a fixed internal standard method. We selected three spots on each sample for general chemical composition.

UV-Vis Spectroscopy. Five diaspore samples (Dia-006a, Dia-006-b, Dia-006-c, Dia-Bur-001, and Dia-Bur-002) were prepared as well-polished, oriented wafers with various thicknesses. UV-Vis spectra were collected with a Perkin-Elmer Lambda 650 UV-Vis spectrophotometer equipped with mercury and tungsten light sources and photomultiplier tube (PMT) detectors installed in an integrating sphere. The spectra were collected at the Gemological Institute, China University of Geosciences in Wuhan. Polarized spectra were collected in the 300-800 nm range with $1 \mathrm{~nm}$ spectral resolution at a scan speed of $267 \mathrm{~nm} / \mathrm{min}$. The spectral baseline was corrected by subtracting spectral offsets at or beyond $800 \mathrm{~nm}$, where the chromophores' features were insignificant or nonexistent. 
TABLE 2. Trace-element composition of diaspore by LA-ICP-MS (in ppma), with standard deviation in parentheses.

\begin{tabular}{|c|c|c|c|c|}
\hline & Dia-006 & Dia-008 & Dia-Bur-001 & Dia-Bur-002 \\
\hline $\begin{array}{l}\text { Trace } \\
\text { element, } \\
\text { with } \\
\text { detection } \\
\text { limit }\end{array}$ & & $E-\ldots$ & & \\
\hline $\mathrm{Ti}-9$ & $110(3)$ & $185(0.9)$ & $220(13)$ & $418(5)$ \\
\hline $\mathrm{V}-0.1$ & $6(0.2)$ & $4(1)$ & $44(2)$ & $359(2)$ \\
\hline $\mathrm{Cr}-1$ & $36(0.7)$ & $32(2)$ & $2166(58)$ & $2081(29)$ \\
\hline $\mathrm{Fe}-20$ & $1169(12)$ & $548(53)$ & 4 (bdl) & 1 (bdl) \\
\hline
\end{tabular}

\section{RESULTS AND DISCUSSION}

Chemical Analysis. Table 2 shows the chemical composition (expressed in ppma) of two diaspore samples from Turkey (Dia-006, Dia-008) and two from Myanmar (Dia-Bur-001, Dia-Bur-002). We concluded that the Burmese samples contained more $\mathrm{Cr}$, while the Turkish diaspore had a higher Fe content. However, the $\mathrm{V}$ content of the Burmese samples was higher than that of the Turkish samples, especially in Dia-Bur-002 (358 ppma).

Raman Spectroscopy. Unlike Turkish diaspore, Burmese material often occurs as thin crystals that are difficult to orient by crystal growth characteristics. However, Raman vibration is closely related to crystal direction (see http://rruff.info/diaspore/ display=default/R060287). By comparing the Raman spectra of the diaspore from Myanmar with the ori- ented sample from Turkey, the Burmese diaspore could be oriented properly. Raman spectra of both the Burmese and Turkish diaspore were collected in the $100-1400 \mathrm{~cm}^{-1}$ range.

According to previous research by Ruan et al. (2001) and San Juan-Farfán et al. (2011), the band at $154 \mathrm{~cm}^{-1}$ is assigned by the rotation of two edgeshared $\mathrm{AlO}_{6}$ octahedra around the c-axis. The most intense peak, at $447 \mathrm{~cm}^{-1}$, is related to Al-O symmetric stretching modes, which means the different polarization direction of the laser has little impact on this peak. Therefore, we normalized the peak intensity at $447 \mathrm{~cm}^{-1}$ and compared the intensity at 154 $\mathrm{cm}^{-1}$. When the polarization direction of the injected laser is parallel to the c-axis, the intensity of the 154 $\mathrm{cm}^{-1}$ peak is much stronger than those that run parallel to the b-axis and a-axis (see note on figure 3). Based on figure 4, we can accurately diagnose the

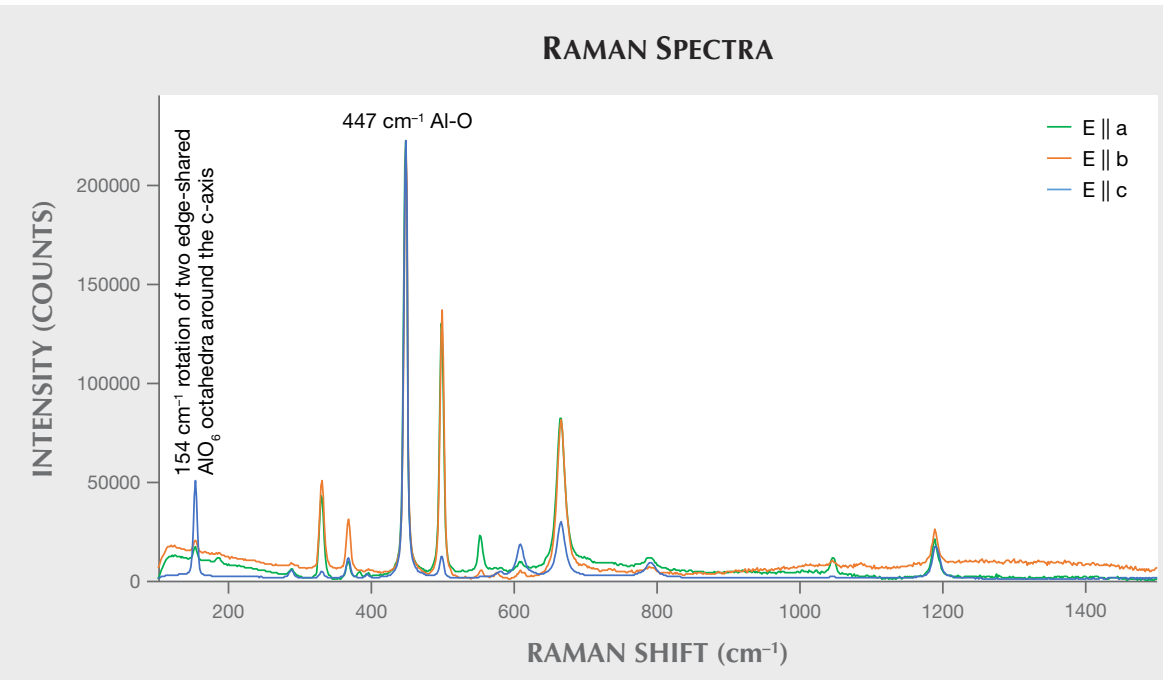

Figure 3. The Raman spectra of the Turkish diaspore, with the polarization direction of the injected laser parallel to the c-axis (blue trace), the b-axis (orange trace), and the $a$ axis (green trace). 


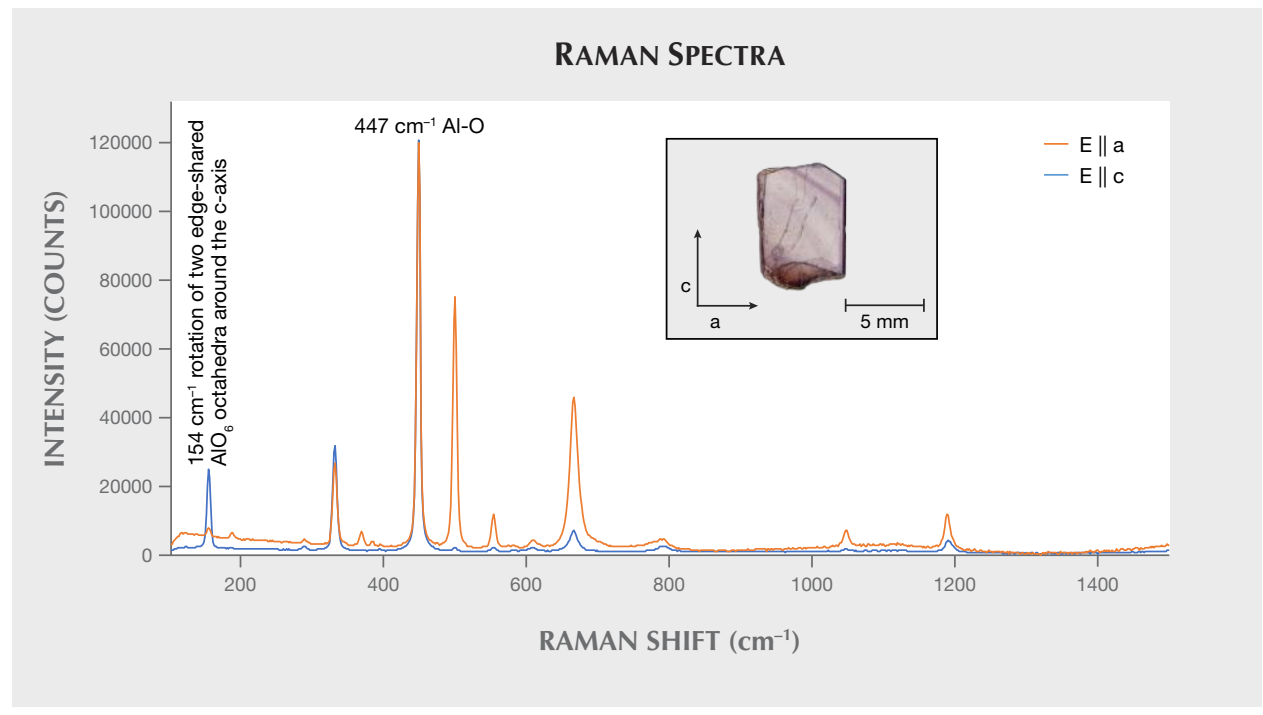

Figure 4. The Raman spectra of Burmese diaspore with the polarization direction of the injected laser parallel to the short side, or aaxis (orange trace), and the c-axis (blue trace).

crystal orientation by Raman vibration $\left(154 \mathrm{~cm}^{-1}\right)$. The Burmese diaspore wafers were manufactured perpendicular to the b-axis based on perfect cleavage along the $\{010\}$ direction. Hence, we can consider the long side of the wafer parallel to the c-axis, and the short side parallel to the a-axis.

UV-Vis and PL Spectroscopy of $\mathbf{C r}^{3+}$. Corundum, a uniaxial crystal, shows dichroism. Its UV-Vis spectra are often collected from two orthogonal orientations with polarized light (o-ray and e-ray). As a biaxial crystal, diaspore shows trichroism; its UV-Vis spectra are collected from three orthogonal orientations with polarized light (E $\|\mathrm{a}, \mathrm{E}\| \mathrm{b}$, and $\mathrm{E} \| \mathrm{c}$ ). In gem cutting, the table of a ruby or sapphire is generally perpendicular to the c-axis. When the polarization direction
(E vector) is parallel to the a-axis, diaspore shows UVvisible absorption features similar to those of corundum (see figure 5). Our corundum samples included three synthetic sapphires-a Cr-bearing synthetic ruby, a Fe-Ti bearing synthetic blue sapphire, a Vbearing color-change sapphire-and one natural yellow Fe-bearing sapphire from Garba Tula, Kenya.

In order to make our initial comparisons between chromophores in corundum and diaspore, we have chosen to compare the spectra of corundum collected from the o-ray (R. Lu, previously unpublished data) with those of diaspore collected from the orientation of polarized light parallel to the a-axis. From LA-ICP-MS data, we know that the Cr content is significantly higher in Burmese samples than in Turkish samples. However, as the Fe content is near

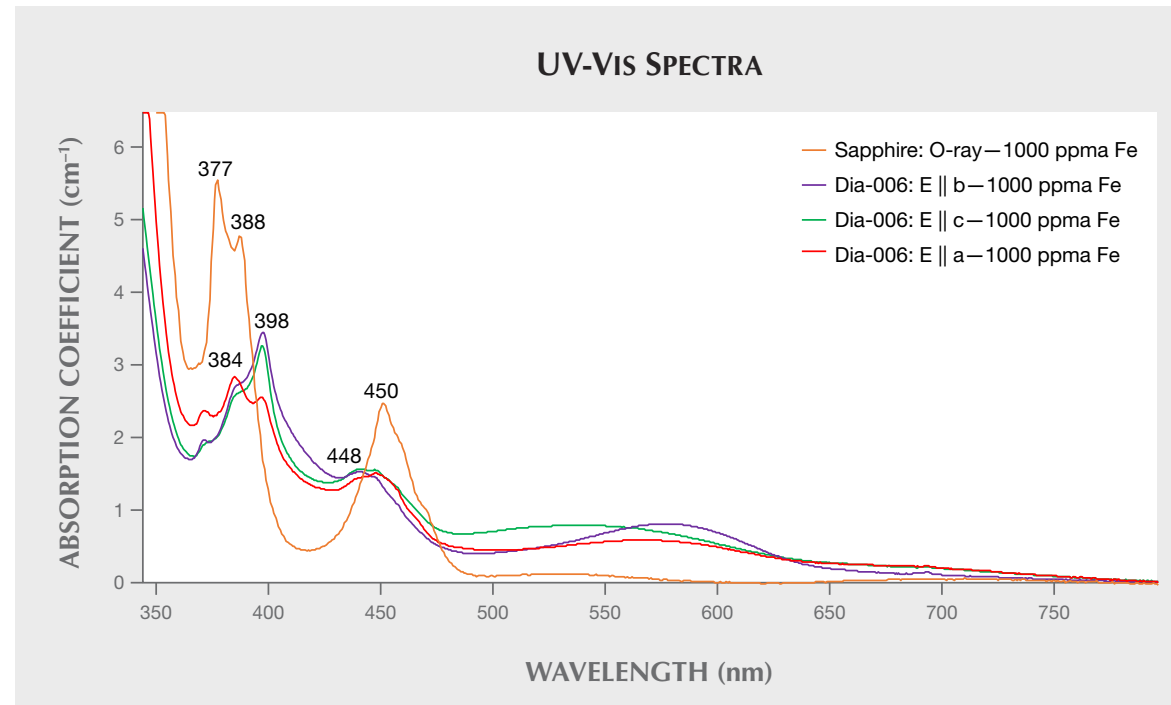

Figure 5. The three polarizations of diaspore ( $E \| a$, $E\|b, E\| c$ ) were collected to compare with the spectra of sapphire (o-ray). Peaks at 377 and $388 \mathrm{~nm}$ in sapphire and at 384 and $398 \mathrm{~nm}$ in diaspore are attributed to $\mathrm{Fe}^{3+}$. The height of sapphire's 377 and 388 $\mathrm{nm}$ peaks (384 and $398 \mathrm{~nm}$ in diaspore) is closely related to directionality. In diaspore, the best match with the spectrum of corundum (o-ray) is shown when the polarization direction is parallel to the $a$ axis $(E \| a)$. 


\section{Box A: Spectral Fitting Based on the Beer-Lambert Law}

There are additive properties that exist in a UV-Vis spectrum. A simple mathematical step will lead to the following equation:

$A=A_{1}+A_{2}+\ldots+A_{n}$

where:

- $A$ is total absorbance of all absorbers

- $A_{1}, A_{2}, \ldots$, and $A_{n}$ are the absorbance of each absorber $n$

Figure A-1 illustrates how this is accomplished.

According to the Beer-Lambert law, the absorption is proportional to the concentration of absorbers (chromophores) through which light passes. It can be expressed simply by the following mathematical expression:

$$
A=1 \sum_{i=1}^{n} \varepsilon_{i} c_{i}
$$

where:
- $A$ is absorbance

- 1 is the path length of the light beam through the material sample

- $\varepsilon_{i}$ is the molar attenuation coefficient or absorptivity of the attenuating species $i$ in the material sample

- $\mathrm{c}_{i}$ is the concentration (in ppma) of the attenuating species $i$ in the material sample

Based on this law, if we have collected the absorption spectrum of a chromophore at a certain thickness, we can simulate absorption spectra of different concentrations and thicknesses within a certain range. Figure 6 shows two spectra of Burmese diaspore. By subtracting the two spectra, we will essentially obtain only the $\mathrm{V}$ absorption since the $\mathrm{Cr}$ concentrations are almost the same. Since we have the pure $\mathrm{V}^{3+}$ spectrum, it is easy to obtain the pure $\mathrm{Cr}^{3+}$ spectrum by subtracting the pure $\mathrm{V}^{3+}$ spectrum from the spectrum of Burmese diaspore.

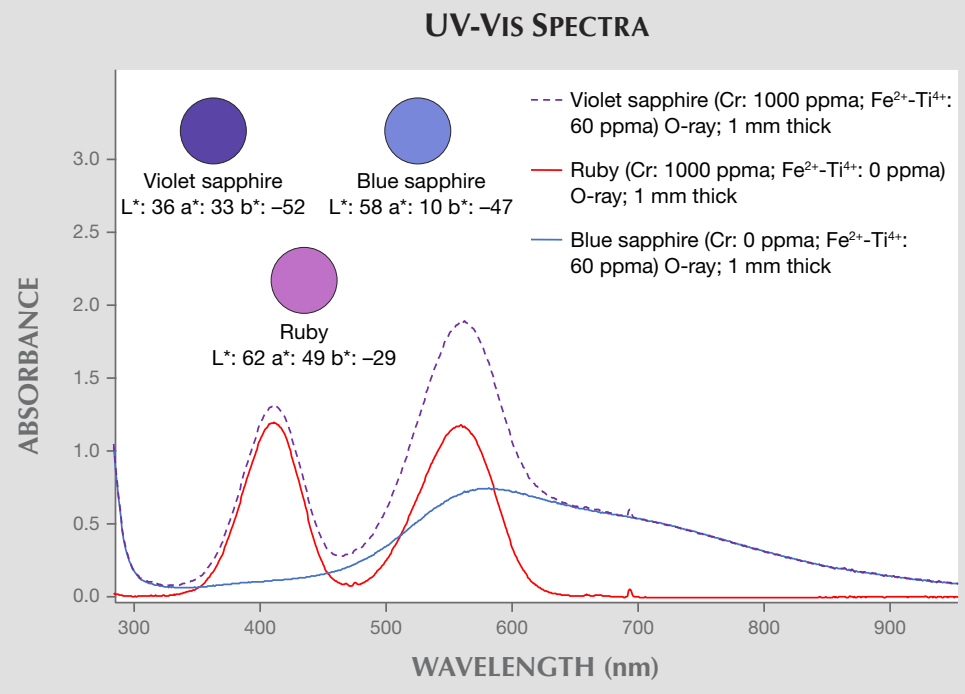

Figure A-1. The absorption of violet sapphire (violet dotted line) shown here represents the sum of the other two spectra: ruby (red line) and blue sapphire (blue line). The color circles calculated under D55 illumination are demonstrated for all of the spectra. We may conclude that violet is a combination of $\mathrm{Cr}^{3+}$ red with $\mathrm{Fe}^{2+}-\mathrm{Ti}^{4+}$ blue. As described above for the additive properties, the absorption of violet sapphire (A) is calculated from two known sets: $A_{1}$ (the absorption of ruby) and $A_{2}$ (the absorption of blue sapphire). However, we could also use the difference $\left(A-A_{1}\right)$ of any two spectra to show the remaining absorption $\left(A_{2}\right)$. zero in the Burmese samples, we disregarded the absorption of Fe in the UV-Vis spectra of that material. The spectra of Dia-Bur-001 and Dia-Bur-002 are shown in figure 6. Although the $\mathrm{Cr}$ content of the two samples is almost the same (2166 and 2081 ppma, respectively), there is a large difference in the absorption intensity. This difference is related to the absorption of vanadium. By subtracting the two spectra, we essentially obtain only $\mathrm{V}$ absorption, which can be subtracted from the other spectra to obtain the pure Cr spectrum (see box A). Based on the author's color analysis, chromium will cause a slight color-change phenomenon in diaspore (figure 7). Additionally, we used the PL spectra (figure 8) to confirm that gem diaspore and ruby show comparable fluorescence spectra (694/693 nm for ruby and $690 / 693 \mathrm{~nm}$ for diaspore).

UV-Visible Spectroscopy of $\mathrm{Fe}^{3+}$ in Diaspore and Sapphire. The UV-Vis spectrum of Turkish diaspore (figure 9) shows features corresponding with those of $\mathrm{Fe}^{3+}$-bearing yellowish sapphire from Garba Tula, 


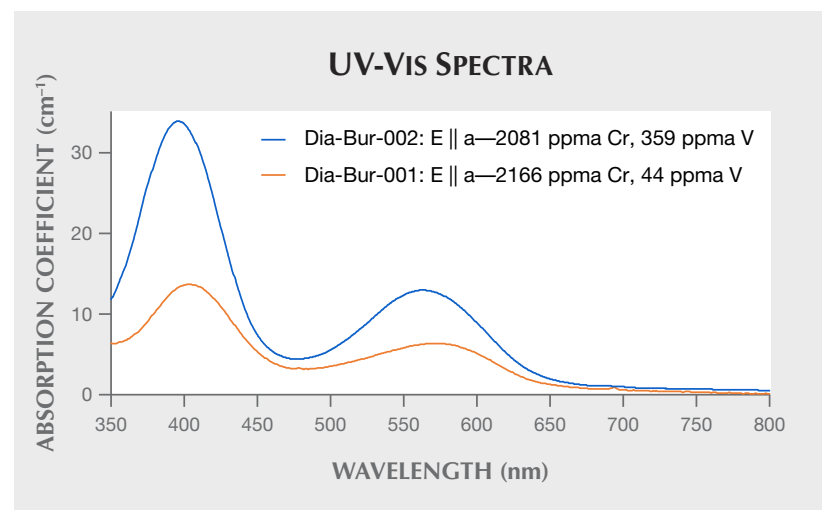

Figure 6. The UV-visible spectra of the Burmese diaspore samples show a large difference in absorption intensity.

Kenya. In those sapphires, the peak at $388 \mathrm{~nm}$ is attributed to $\mathrm{Fe}^{3+}$, while the peaks at 377 and $450 \mathrm{~nm}$ are attributed to $\mathrm{Fe}^{3+}-\mathrm{Fe}^{3+}$ pairs (Ferguson and Fielding, 1971, 1972; Krebs and Maisch, 1971). The spectra of diaspore show features very similar to those of $\mathrm{Fe}^{3+}$-bearing sapphire. Hence, the peaks at 384 and $448 \mathrm{~nm}$ are attributed to $\mathrm{Fe}^{3+}-\mathrm{Fe}^{3+}$ pairs, and the peak at $398 \mathrm{~nm}$ is attributed to $\mathrm{Fe}^{3+}$.

UV-Visible Spectroscopy of $\mathrm{Fe}^{2+} \mathrm{Ti}^{4+}$ Pairing in Diaspore and Sapphire. The UV-Vis spectra of the Turkish

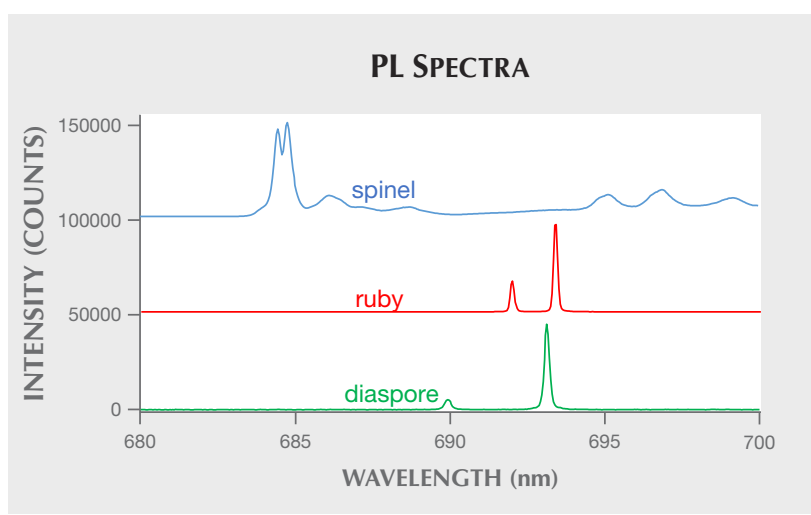

Figure 8. The PL spectra of natural ruby and one of the Burmese diaspore samples show very similar characteristics based on table 1. The crystallographic parameters of diaspore are very close to those of ruby, but quite different from those of spinel. The PL spectra of spinel (data provided by Dr. Chengsi Wang) are considerably different from those of ruby and diaspore. Therefore, we can also use PL spectra to demonstrate that the structural units of diaspore and ruby are very closely related.

diaspore show an obvious absorption band at around $570 \mathrm{~nm}$. Based on the LA-ICP-MS data, chromium and vanadium are very low in Turkish diaspore. In blue sapphire, the absorption at around $580 \mathrm{~nm}$ is attributed

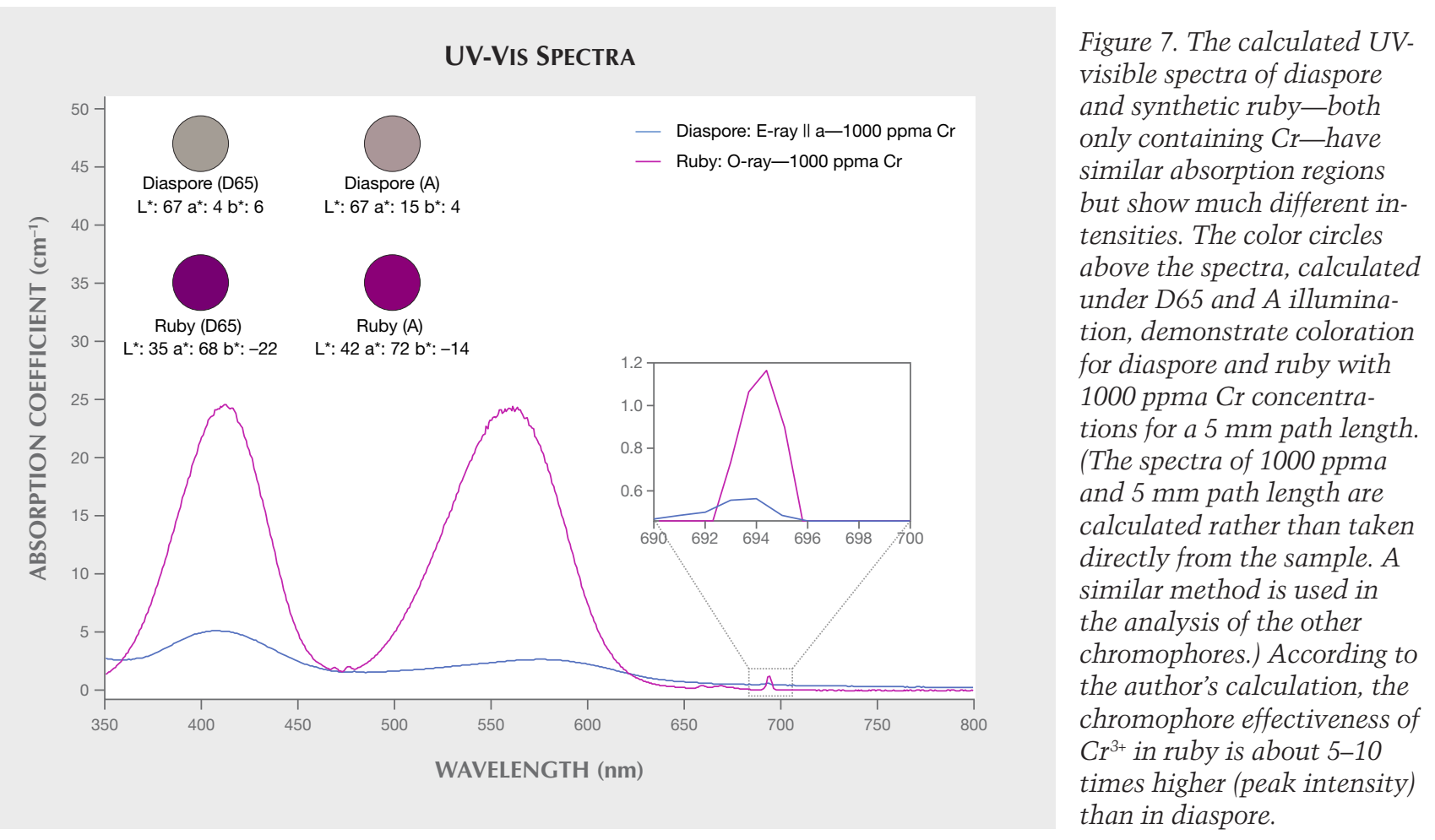




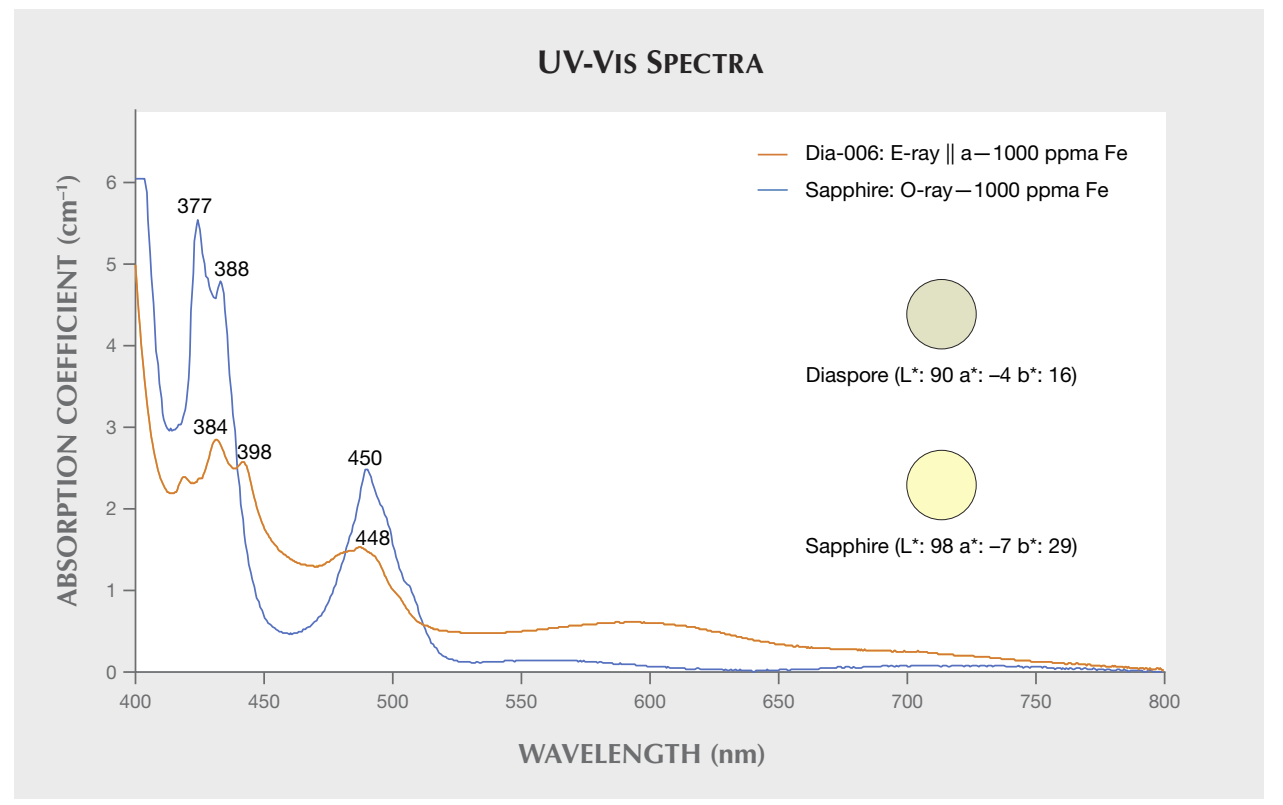

Figure 9. The UV-visible spectra of Turkish diaspore and yellowish sapphire from Garba Tula, Kenya, exhibit closely matched $a b$ sorption features, especially when polarized light is parallel to the a-axis. The color circles are calculated under D55 illumination, demonstrating the coloration for diaspore and sapphire with 1000 ppma Fe concentrations for a $5 \mathrm{~mm}$ path length. According to the author's calculation, the chromophore effectiveness of $\mathrm{Fe}^{3+}$ in sapphire is about 1.6 times higher (peak intensity) than in diaspore.

to an $\mathrm{Fe}^{2+}-\mathrm{Ti}^{4+}$ pairing (Emmett et al., 2003). It is possible that the absorption at around $570 \mathrm{~nm}$ in diaspore is related to $\mathrm{Fe}^{2+}-\mathrm{Ti}^{4+}$ (see figure 10). In blue sapphire, the absorption of the $\mathrm{Fe}^{2+}-\mathrm{Ti}^{4+}$ pair does not cause the color-change effect because the absorption band ex- tends to the near-infrared region, so the transmission rate of red areas and green areas is not relatively equal. But in diaspore, these transmission areas are fairly equal. The value of $a^{\star}$ has changed from -3 to 1 , which means the color will change from green to red.

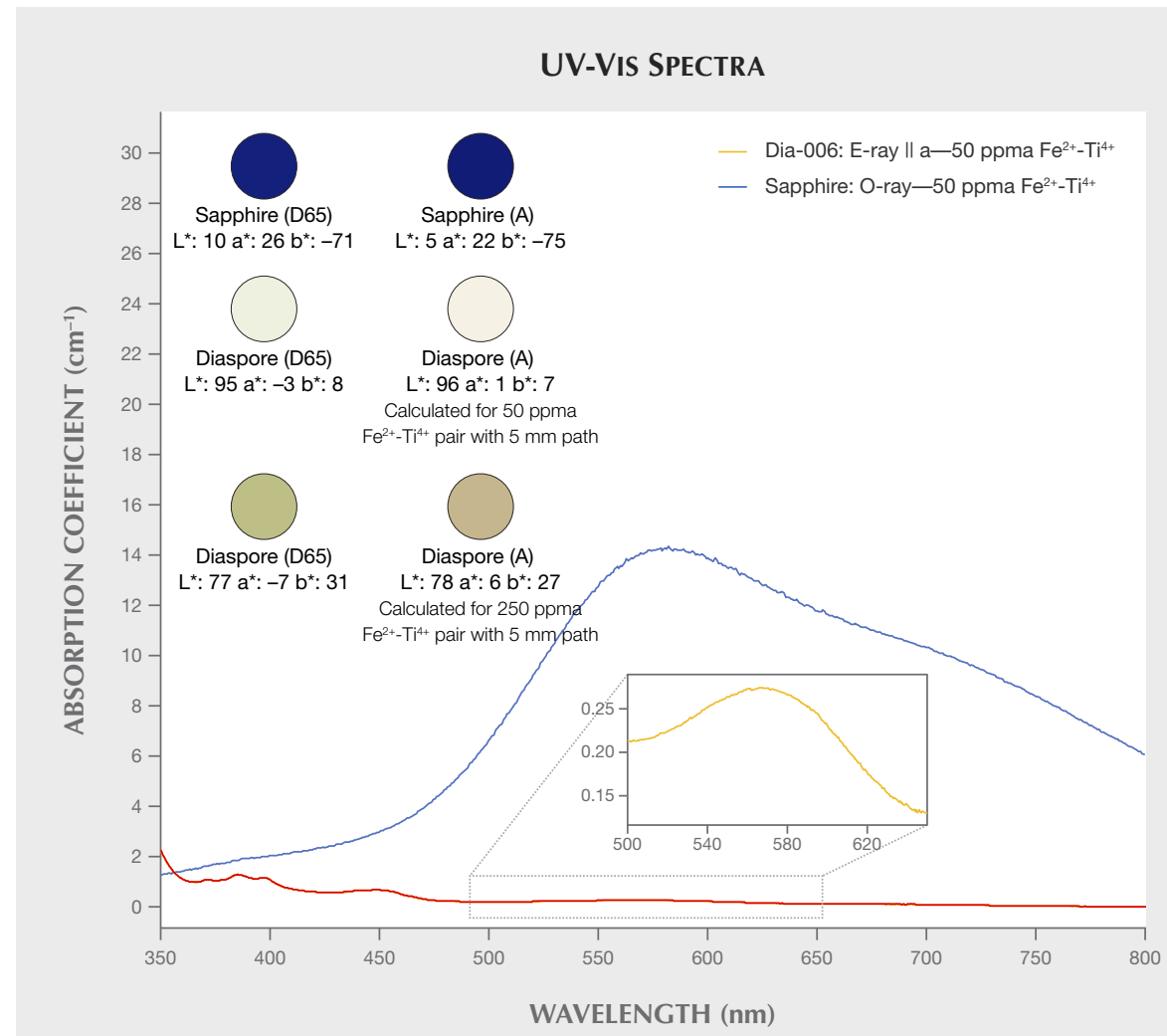

Figure 10. The UV-visible spectra of Turkish diaspore and blue synthetic sapphire (containing $\mathrm{Fe}^{2+}-\mathrm{Ti}^{4+}$ only). The two spectra have similar absorption regions but show much different absorption intensities. The color circles, calculated under D65 and A illumination, demonstrate the coloration for sapphire and diaspore with $50 \mathrm{ppma}$ $\mathrm{Fe}^{2+}-\mathrm{Ti}^{4+}$ pair concentrations for a $5 \mathrm{~mm}$ path length. Since the color swatches of diaspore calculated using 50 ppma concentration of $\mathrm{Fe}^{2+}$ Tiं pairs do not show a clear color change, we must calculate the colors, which are shown in the spectra, at a higher concentration of $\mathrm{Fe}^{2+}$ $\mathrm{Ti}^{4+}$ pairs (250 ppma) for a 5 $\mathrm{mm}$ path length. The chromophore effectiveness of the $\mathrm{Fe}^{2+}-\mathrm{Ti}^{4+}$ pair is about 50 times higher (peak intensity) in sapphire. 


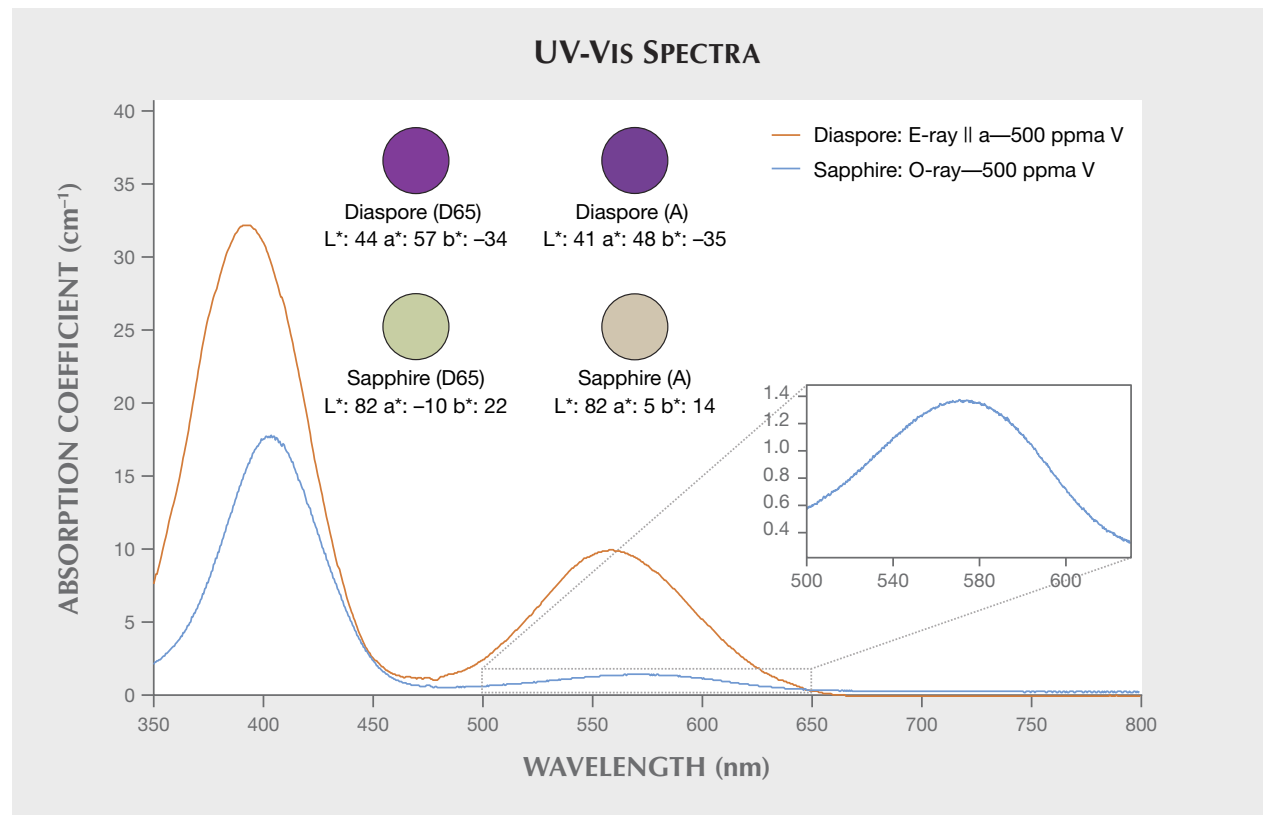

Figure 11. The UV-visible spectra of diaspore (after calculation) and synthetic sapphire (containing $V$ only). The two spectra show similar absorption regions but different absorption intensities. The color circles are calculated under D65 and A illumination and demonstrate coloration for sapphire and diaspore with 500 ppma $\mathrm{V}$ concentrations for a $5 \mathrm{~mm}$ path length. According to the author's calculation, the chromophore effectiveness of $V^{3+}$ in diaspore is about 2-7 times higher (peak intensity) than in sapphire.

Emmett et al. (2017) proposed that Si plays a role in the color chemistry of corundum. If corundum contains $\mathrm{Ti}, \mathrm{Si}, \mathrm{Mg}$, and $\mathrm{Fe}$, the Fe will pair with $\mathrm{Si}$ before Ti. If diaspore is similar to corundum, Fe will chargecompensate Si before Ti. However, the instruments used for LA-ICP-MS show significant interferences for the three silicon isotopes (Shen, 2010), and as a result the Si content is higher than the value shown. The author does not take $\mathrm{Si}$ into consideration because of this instrumental error, and assumes that all of the Ti pairs with Fe. Therefore, the actual content of the $\mathrm{Fe}^{2+}-\mathrm{Ti}^{4+}$ pair may be lower than the content determined through analysis.

UV-Visible Spectroscopy of $\mathbf{V}$ in Diaspore and Sapphire. In natural corundum, vanadium content is generally very low. Synthetic sapphire, which has been manufactured with V, will show an obvious colorchange effect. This type of synthetic sapphire is similar to natural alexandrite. However, there is some V in natural diaspore from Myanmar, which plays an important role in color origin and color change.

We compared the spectra of diaspore /containing $\mathrm{V}$ only; see box A) to pure vanadium-bearing syn- thetic sapphire. They also show similar absorption characteristics in their UV-Vis spectra, as both peaks are at around $400 \mathrm{~nm}$ and $560 \mathrm{~nm}$ in diaspore and sapphire (see also figure 11).

\section{CONCLUSIONS}

In color-change diaspore, $\mathrm{Cr}^{3+}, \mathrm{V}^{3+}$, and $\mathrm{Fe}^{2+}-\mathrm{Ti}^{4+}$ pairs are the chromophores, and all of these contain an absorption area at around $560-580 \mathrm{~nm}$. These chromophores may all play a role in causing the color-change effect. Raman spectroscopy proved to be a powerful tool for determining the crystal orientation of the Burmese diaspore wafer; it is also useful to measure and compare the directional UV-Vis spectra of diaspore and corundum. Because of their structural similarity, we can confirm the color correlation between corundum and diaspore and compare the effectiveness of the chromophores. According to the calculation, the chromophore effectiveness of $\mathrm{Cr}^{3+}$, $\mathrm{Fe}^{3+}$, and $\mathrm{Fe}^{2+}-\mathrm{Ti}^{4+}$ in corundum is about 5-10, 1.6, and 50 times higher, respectively, than in diaspore. However, the chromophore effectiveness of $\mathrm{V}^{3+}$ in diaspore is approximately $2-7$ times higher than in corundum.

\section{ABOUT THE AUTHORS}

Mr. Shen is a graduate student at the Gemmological Institute, China University of Geosciences in Wuhan. In 2018, he was a research intern at the Gemological Institute of America in Carlsbad, California. Dr. Lu is a professor at the Gemmological Institute, China University of Geosciences in Wuhan.

\section{ACKNOWLEDGMENTS}

The authors would like to thank Mr. Yungui Liu at HGTC (Gemstone Center of Hebei GEO University) provided Raman and PL testing. Dr. Aaron Palke (GIA, Carlsbad) and anonymous peer reviewers provided many helpful comments and suggestions. 


\section{REFERENCES}

Deflandre M. (1932) La structure cristalline du diaspore. Bulletin de la Société Française de Minéraologie et de Cristallographie, Vol. 55, pp. 140-165.

Emmett J.L., Scarratt K., McClure S.F., Moses T., Douthit T.R., Hughes R., Novak S., Shigley J.E., Wang W., Bordelon O., Kane R.E. (2003) Beryllium diffusion of ruby and sapphire. $G \uplus G$, Vol. 39, No. 2, pp. 84-135, http://dx.doi.org/10.5741/GEMS. 39.2.84

Emmett J.L., Stone-Sundberg J., Guan Y., Sun Z. (2017) The role of silicon in the color of gem corundum. $G \uplus G$, Vol. 53, No. 1, pp. 42-47, http://dx.doi.org/10.5741/GEMS.53.1.42

Ferguson J., Fielding P.E. (1971) The origins of the colours of yellow, green and blue sapphires. Chemical Physics Letters, Vol. 10, No. 3, pp. 262-265.

Ferguson J., Fielding P.E. (1972) The origins of the colours of natural yellow, blue, and green sapphires. Australian Journal of Chemistry, Vol. 25, No. 7, pp. 1371-1385.

Francombe M.H., Rooksby H.P. (1959) Structure transformations effected by the dehydration of diaspore, goethite and delta ferric oxide. Clay Minerals, Vol. 4, pp. 1-14, http://dx.doi.org/ 10.1180/claymin.1959.004.21.01

Hill R.J. (1979) Crystal structure refinement and electron density distribution in diaspore. Physics and Chemistry of Minerals, Vol. 5, No. 2, pp. 179-200, http://dx.doi.org/10.1007/ BF00307552

Iwai S.I., Yamamoto H., Morikawa H., Isobe M. (1973) Topotactic thermal-transformation of diaspore to corundum. Mineralogical Journal, Vol. 7, No. 2, pp. 137-158, http://dx.doi.org/ 10.2465/mineri1953.7.137

Krebs J.J., Maisch W.G. (1971) Exchange effects in the optical-ab- sorption spectrum of $\mathrm{Fe}^{3+}$ in $\mathrm{Al}_{2} \mathrm{O}_{3}$. Physical Review B, Vol. 4 No. 3, p. 757.

Lewis J., Schwarzenbach D., Flack H.D. (1982) Electric field gradient and charge density in corundum, $\alpha-\mathrm{Al}_{2} \mathrm{O}_{3}$. Acta Crystallographica, Vol. 38, No. 5, pp.733-739, http://dx.doi.org/10.1107/ S0567739482001478

Lu R. (2012) Color origin of lavender jadeite: An alternative approach. Ge G, Vol. 48, No. 4, pp. 273-283, http://dx.doi.org/ 10.5741/GEMS.48.4.273

Malsy A.K. (2012) Orangey-red to orangey-pink gem spinels from a new deposit at Lang Chap (Tan Huong-Truc Lau), Vietnam. Journal of Gemmology, Vol. 3, No. 1, pp. 19-27, http://dx.doi.org/10.15506/JoG.2012.33.1.19

Peterson R.C., Lager G.A., Hitterman R.L. (1991) A time-of-flight neutron powder diffraction study of $\mathrm{MgAl}_{2} \mathrm{O}_{4}$ at temperatures up to 1273 K. American Mineralogist, Vol. 76, No. 9-10, pp. $1455-1458$.

Ruan H.D., Frost R.L., Kloprogge J.T. (2001) Comparison of Raman spectra in characterizing gibbsite, bayerite, diaspore and boehmite. Journal of Raman Spectroscopy, Vol. 32, No. 9, pp. 745-750, http://dx.doi.org/10.1002/irs.736

San Juan-Farfán R.E., Bayarjargal L., Winkler B., Haussühl E., Avalos-Borja M., Refson K., Milman V. (2011) Pressure dependence of the lattice dynamics of diaspore, $\alpha-\mathrm{AlO}(\mathrm{OH})$, from Raman spectroscopy and density functional perturbation theory. Physics and Chemistry of Minerals, Vol. 38, No. 9, pp. 693700, http://dx.doi.org/10.1007/s00269-011-0442-3

Shen A.H. (2010) Silicon in sapphires-its role and detectability by LA-ICP-QMS. Goldschmidt Conference Abstracts 2010, p. A945.

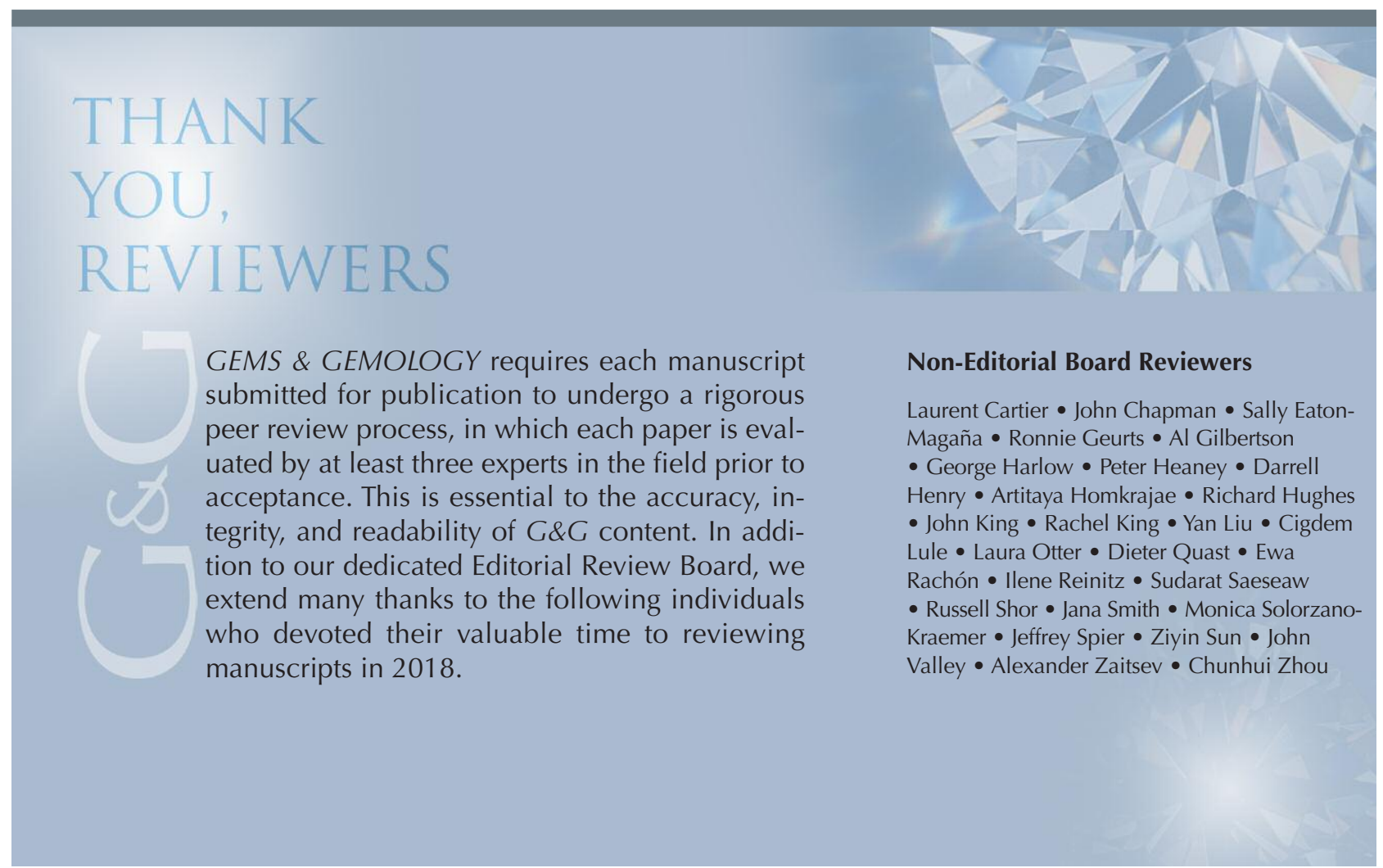

